\title{
Configurações
}

Revista de sociologia

\section{Cancro, arte e ação: experiências e projetos de mulheres e homens Portugueses}

Cancer, art and action: experiences and projects of Portuguese women and men Cancer, art et action: expériences et projets chez les hommes et femmes Portugais

\section{Susana Noronha}

\section{OpenEdition}

\section{Journals}

Electronic version

URL: http://journals.openedition.org/configuracoes/6097

DOI: 10.4000/configuracoes.6097

ISSN: 2182-7419

\section{Publisher}

Centro de Investigação em Ciências Sociais

Printed version

Number of pages: 101-116

ISSN: 1646-5075

\section{Electronic reference}

Susana Noronha, "Cancro, arte e ação: experiências e projetos de mulheres e homens Portugueses ", Configurações [Online], 22 | 2018, Online since 21 December 2018, connection on 02 May 2019. URL : http://journals.openedition.org/configuracoes/6097 ; DOI : 10.4000/configuracoes.6097 
Noronha, Susana - Cancro, arte e ação: experiências e projetos de mulheres e homens Portugueses. Configurações, vol. 22, 2018, pp. 101-116.

\title{
Cancro, arte e ação: experiências e projetos de mulheres e homens Portugueses
}

SUSANA NORONHA*

CES - Universidade de Coimbra

\section{Resumo}

Este texto centra-se nas experiências e nos projetos de mulheres e homens Portugueses que dão uso à arte como modo de construir sentido e ação sobre a doença oncológica. Que tipo de resultados e consequências poderão advir ao nível social da criação e apresentação pública destes projetos? Que tipo de conhecimento podemos construir sobre o cancro, partindo da perspectiva combinada da ciência social e da arte? Pode a mistura de conhecimentos incorporados, artísticos e científicos alargar a forma como entendemos as pessoas doentes, o cancro e a arte? Teoricamente, este estudo antropológico desdobra um entendimento epistemológico e ontológico da arte, redefinindo-a como um acrescento de experiência, conhecimento e ação.

Palavras-chave: cancro, conhecimento incorporado, arte, ação.

\begin{abstract}
Cancer, art and action: experiences and projects of Portuguese women and men This text focuses on the experiences and projects of Portuguese women and men who use art as a way to build meaning and take action on cancer. What kind of social results and consequences can the production and public presentation of these projects entail? Regarding cancer, what kind of knowledge can we build from the combined perspectives of social science and art? Can the blend of embodied, artistic and scientific knowledge broaden the way we understand those who are sick, cancer and art?
\end{abstract}

*E-mail: susananoronha@ces.uc.pt 
Theoretically, this anthropological study unfolds an epistemological and ontological understanding of art, redefining it as additional experience, knowledge and action.

Keywords: cancer, embodied knowledge, art, action.

\section{Résumé}

Cancer, art et action: expériences et projets chez les hommes et femmes Portugais

Ce texte est centré sur les projets d'hommes et de femmes portugais, qui utilisent l'art comme un moyen de susciter une prise de conscience et d'engendrer des actions concernant les maladies cancéreuses. Quel type de conséquences pourront découler, du point de vue social, de la présentation publique de ces projets ? Quel type de connaissances pouvons-nous tirer du cancer, du point de vue des sciences sociales et de l'art ? Le mélange de savoirs incorporés, artistiques et scientifiques, peut-il élargir notre entendement des personnes malades, du cancer et de l'art ? Du point de vue théorique, cette étude anthropologique dévoile une compréhension épistémo-ontologique de l'art, en le redéfinissant comme une addition d'expérience, de connaissance et d'action.

Mots-clés: cancer, savoir incorporé, art, action.

\section{Introdução}

Para responder às interrogações que norteiam este texto, e justificar a sua pertinência, é necessária uma retrospectiva através das abordagens teóricas que uniram a antropologia e a sociologia médica aos estudos sociais da arte na análise das ligações entre o cancro e as artes plásticas e visuais. Os livros e autores que abastecem os estudos antropossociológicos da arte e da doença são muitos, mas continuam a ser poucas ou quase nenhumas as investigações que procuram os seus encaixes. Os projetos e narrativas artísticas sobre experiências de cancro são raramente abrangidos pela literatura das ciências sociais. Todavia, uma história pode ser contada sem palavras, dependendo exclusivamente de uma sequência de imagens ou objetos. Indo além das expressões orais e escritas, um pequeno número de ensaios tem analisado a forma como as histórias de doença podem ser contadas através de fotografias (Radley, 2002, 2009), vídeos, desenhos e pinturas (Bolaki, 2017). Mas como pode o cancro ser transformado em arte? De que forma pode a arte refazer ou redefinir a doença oncológica? Como tem respondido a investigação em ciência social a este impacto bidirecional?

As primeiras teorizações resultam de experiências vividas em primeira mão e escritas na primeira pessoa, saídas da vida de artistas com a doença (Spence, 1986, 1995; Wilke, 1995), mulheres que usaram conhecimentos incorporados e artísticos para intervir sobre o cancro da mama, a leucemia e o linfoma. A investigação em ciências sociais sobre as ligações estabelecidas entre arte(s) e cancro(s) é residual e empiricamente limitada às mulheres e ao cancro da 
mama (Bell, 2002, 2006; Radley, 2007). A maior parte da literatura existente é formada por uma pequena lista de artigos focados em obras de arte criadas por um número extremamente reduzido de mulheres artistas, repetindo os nomes e as histórias de criadoras Britânicas e Norte-Americanas como Hannah Wilke, Jo Spence, Martha Hall ou Matuschka. Embora influentes no mundo $\mathrm{da}$ arte e diretamente associadas às primeiras fotografias e obras de arte relacionadas com o cancro, esta pequena lista de nomes foi ampliada por uma multidão consecutivamente ignorada pelos estudos sociais da arte e da doença. A maioria destes estudos estreita o seu foco em torno da fotografia e do cancro da mama, dos peitos assimétricos às cicatrizes de mastectomias radicais (Bell, 2002, 2006; DeShazer, 2015; Radley, 2007), deixando de lado a diversidade das muitas artes plásticas e visuais utilizadas por doentes e sobreviventes/ resistentes. A restante literatura científica dá atenção aos projetos gráficos da banda desenhada, contando histórias de cancro em desenhos às tiras e balões de texto (McMullin, 2016), “extraídas da vida”, lembrando pessoas, apagando a morte (O’Brien, 2013). Estas histórias apontam para as potenciais realizações de pessoas doentes e obras de arte no contexto da saúde e do ativismo oncológico, ou seja, envolvendo-se na consciencialização e mobilização comunitária contra a doença maligna. Trata-se de "fazer arte para construir sentido" (Bell, 2006), "documentando órgãos pós-operatórios" (DeShazer, 2015), narrando experiências (Bell, 2002), multiplicando os possíveis significados da doença (DeShazer, 2015) e "reivindicando justiça social” (Radley, 2007). À margem da literatura científica, uma outra literatura resulta da agência de artistas, usando livros e catálogos para expor imagens de vidas e corpos transformados pelo cancro e pelo tratamento, da resistência à remissão.

Alguns dos hiatos na literatura foram preenchidos por duas investigações conduzidas em Portugal (Noronha, 2009, 2015) sobre narrativas e projetos artísticos internacionais criados em torno da experiência do cancro, procurando os usos e os sentidos dados por artistas e mulheres doentes a estas criações. Contrariando o conceito simplista que a define como uma representação do real, a arte, enquanto objeto ou projeto, foi entendida como uma parte constitutiva da própria experiência, entranhada na forma como se vive, compreende e age sobre o cancro da mama (Noronha, 2009, 2018). Enquanto conhecimento e prática interventiva, a arte mostra-se aplicável não apenas nos processos individuais de confronto com a doença, mas também em ações de informação, reivindicação e ativismo movidas por ambições sociais, ou seja, a arte como promotora de mudança na forma como entendemos e agimos sobre o cancro, da prevenção ao tratamento e acompanhamento. Estas investigações também abriram o campo de análise a projetos artísticos referentes à experiência dos muitos outros cancros que crescem nos nossos órgãos e partes de corpo (Noronha, 2015), comentando malignidades para além da mama e das suas patologias. Embora tenham resultado nas primeiras monografias escritas 
e publicadas sobre as representações da doença oncológica nas artes plásticas e visuais, estas investigações mantêm o foco no cancro da mama (Noronha, 2009) e na experiência de mulheres maioritariamente provenientes do Norte da América e da Europa (Noronha, 2015), onde Portugal, exceptuando um único projeto artístico, se desenha como um vazio ou ausência.

Preenchendo uma lacuna na literatura, este texto pretende precisamente agregar essas representações artísticas da doença oncológica, comentando os projetos artísticos existentes em Portugal. Metodologicamente, resulta de um exercício de investigação qualitativo informado pela fotografia, pelo vídeo e pelo desenho, abastecendo-se dos seus conhecimentos e potencial discursivo (Butler-Kisber, 2010). A inovação desta abordagem prende-se com o facto de combinar os estudos sociais da arte e da doença, recolhendo fontes empíricas ausentes do estudo antropológico ou sociológico do cancro - projetos artísticos sobre a doença, criados por mulheres e homens Portugueses. Dando uso a métodos visuais e digitais, explora-se a versão online destes projetos artísticos, juntando-lhe as informações dos seus textos explicativos, títulos, sinopses e legendas (Banks, 2015; Pink, 2005; Woodward, 2007), aproveitando este exercício de triangulação (Denzin, 2017, Mason, 2002) para robustecer o estudo.

Reconhecendo a validade de formas de conhecimento existentes para lá da ciência, somos empurrados a procurar tudo o que se encaixa nas margens e nas entrelinhas, reduzindo as "ausências" e procurando as "experiências desperdiçadas” (Santos, 2003, 2007). Teórica e metodologicamente, este texto parte da vida de mulheres e homens com doenças oncológicas, dos seus pontos de vista e conhecimento situado (Haraway, 2004; Harding, 1991, 2004), reunindo e apresentando testemunhos de experiências e formas de cancro ausentes das ciências sociais, abrindo áreas de reflexão inexistentes em anteriores abordagens. A soma das perspectivas parciais destas pessoas e projetos (Haraway, 2004) poderá abranger uma maior parcela da realidade oncológica Portuguesa, dando à ciência social uma oportunidade para repensar gente com cancro, doença, arte e conhecimento, do incorporado ao científico. Aceitando a incompletude e o caráter situado do conhecimento antropológico e sociológico (Haraway, 2004; Harding, 2004; Santos, 2004), procura-se um saber que (re)misture o conhecimento vivido, científico e artístico na construção de sentido e ação sobre a doença oncológica. Enfatizando o que podemos ganhar ou encontrar na sua mistura (Gray, 2002; Schneider, 2010, 2017), ambiciona-se um alargamento transdisciplinar do entendimento antropossociológico, contribuindo, assim, para os avanços teóricos em torno das relações e ligações entre arte e ciência (Abbot, 2007; Schneider, 2005). 


\section{As fotografias, os vídeos e as histórias de mulheres com cancro da mama}

Em Portugal, tanto a literatura científica como os projetos artísticos sobre cancro são infrequentes. Com menos de uma década de existência, estes projetos foram, até agora, descurados pela ciência social. São, na maioria, ensaios fotográficos centrados no cancro da mama, repetindo a centralidade desta tipologia de cancro e deste meio visual na representação da doença. A generalidade destes projetos tem recebido a atenção da imprensa escrita e dos meios de comunicação audiovisuais, alvo do interesse de repórteres ou mesmo coautorados por fotojornalistas. Embora alguns tenham uma existência externa a computadores e lugares digitais, todos estes projetos encontram abertura nas páginas da Internet, onde os seus possíveis espectadores e leitores se podem alargar numa multidão de muitos milhares. O projeto que antecedeu todos os outros, apresentado online em Maio de 2011, foi também o único a receber atenção da investigação em ciências sociais (Noronha, 2015). A autoria conceptual é de Alexandra Silva e as fotografias de Eduardo Basto (Silva e Basto, 2011). Alexandra pediu a Eduardo que lhe emprestasse os olhos e as mãos para apanhar, em câmara, a história das transformações que se foram desenhando no seu corpo durante o tratamento a dois cancros da mama, vividos em simultâneo, nas duas metades do seu peito. Instaladas numa URL da plataforma "Tumblr", as fotografias de "My Body is a Cage" apanham excertos despidos da sua história, a "forma que encontrou para reagir à doença”, sob a indelével ameaça genética do BRCA1 e BRCA2, mutações que aumentam a susceptibilidade de desenvolver cancro da mama, mas também o risco de uma recidiva. Dos efeitos das mastectomias e ciclos de quimioterapia, da cabeça às mamas, do corpo à vida, estendem-se, a preto e branco, as marcas, cicatrizes e implantes encastrados numa história sem "fim" agendado.

Ainda em 2011 surgia o projeto "Retrato de Mim”, numa parceria entre o Movimento de Expressão Fotográfica e a Associação Portuguesa de Apoio à Mulher com Cancro da Mama (MEF e APAMCM, 2011). Com a intenção de mobilizar recursos para enfrentar e desmistificar a doença oncológica mamária, "Retrato de Mim" foi exposto em espaços físicos e online, reproduzido na revista "Cais" de Setembro de 2012, multiplicando também o seu público em reportagens televisivas. A cores ou a preto e branco, com ou sem rosto, com ou sem cabelo, abrem-se as histórias e as camisas de algumas mulheres com cancro da mama, todas com nome próprio e muitas com apelido, misturando fotografia e testemunho escrito, estendido das cicatrizes, próteses e implantes às perdas e vitórias que cabem no peito e na mão. Em finais de 2012, o projeto “Nu Enfermo” juntava a neta, Bruna Amaral, à sua avó, Amélia Conde, expondo um corpo e uma mama direita apertada e atravessada pela cicatriz de uma mastectomia (Amaral e Conde, 2012). As fotografias em nu integral, 
convertidas para blog, página de rede social, vídeo e exposição em galeria, pretendem contrariar o preconceito e o estigma social imposto à mulher com cancro e ao corpo mastectomizado. Com uma crueza visual sem comparação nos restantes projetos portugueses, Bruna fotografou o corpo de Amélia sem roupa nem acanhamento, decorada apenas com um colar e um par de brincos, rematados pelo verniz cor-de-rosa que lhe pinta as unhas. Um vídeo teaser apanha o movimento de uma Amélia que se despe, lembrando que na rua, debaixo das peças de roupa, o cancro não pode ser partilhado, visto ou compreendido.

A campanha fotográfica "Breast Cancer, Live to Tell", anteriormente "100 Mulheres 100 cancro”, iniciada em 2011 pelo fotógrafo Gonçalo Cunha de Sá numa colaboração entre o projeto "Mulheres Portuguesas" e o "Movimento Rosa Esperança”, obteve a colaboração de cem mulheres portuguesas com cancro da mama (Cunha de Sá, 2011). Com o objetivo da consciencialização pública, promovendo a prevenção e detecção precoce, a campanha recolheu não apenas os rostos e torsos destas mulheres, mas também as suas palavras e testemunhos, com a intenção de dar forma, em 2016, a um documentário vídeo, somado às fotografias já existentes, alargando a "mensagem de coragem, esperança e amor”, proposta pelo autor. Em 22 de Junho de 2013 o Jornal Expresso publicava na sua capa a fotografia de uma mulher mastectomizada, Fátima Medeiros, apanhada pela objetiva da fotógrafa Ana Baião (Baião e Martins, 2013). Uma reportagem sobre "Cicatrizes para a Vida”, de Cristiana Martins, trouxe Fátima à sessão fotográfica em estúdio, entre medo e família, ao lado da filha. Com coragem, em frente a estranhas, "disposta a enfrentar", despiu-se, expôs-se, olhou para as fotografias no ecrã e no papel, encarando a cicatriz pela primeira vez. Vista por milhares, foi capa de revista, a primeira em Portugal, sente e sabe que "ajudou outras pessoas".

Em Abril de 2013, dois fotógrafos amadores, Nádia Morado e Tiago Braga, uniram a sua "Fotografia Solidária" à Associação Oncológica do Algarve para darem forma ao "Calendário AOA 2014", um "Projeto de Luta Contra o Cancro" (Morado e Braga, 2014). Vestidas e maquilhadas para as sessões fotográficas, as doze mulheres fotografadas mostram que o cancro não escolhe meses, embora elas possam escolher como viver os seus dias. Cada mês tem o corpo e o nome de uma, duas, três ou quatro mulheres, agarradas a palavras de força, escritas em tons claros sobre fundo negro. $\mathrm{O}$ cancro pode ser vivido em grupo, transformado em formato A4, num calendário de luta que pede o contributo de todos/as para a "defesa dos doentes oncológicos". Com este mesmo objetivo, os mesmos fotógrafos duplicaram os seus esforços para um calendário de 2015, juntando mulheres e homens com experiências de cancro, contando as suas histórias no "Once Upon a Dream" (Morado e Braga, 2015). Era uma vez um sonho, quinze histórias em doze meses, empurrando o cancro para um "conto de fadas", um monstro feio, feito pequeno por quem consegue ser "feliz para sempre", até ao "Fim". As fotografias de cores felizes 
e as frases que lhes dão texto, repetem a ideia de uma atitude positiva contra o cancro, calando o lado negativo da doença. Tiago Braga alargou o conceito destes primeiros dois projetos e lançou “Na Minha Pele”, em 2016, juntando entrevistas vídeo às fotografias de gente com cancro e com garra, mulheres e homens com histórias diferentes, sempre parecidas, com um ponto final feliz (Braga, 2016).

"Acredita! És muito mais do que o teu cabelo! Não é o cabelo que te assusta... é o cancro. Confia! Vai dar tudo certo!” As palavras são ditas algures entre um cancro e os fios de cabelo de uma mulher chamada Sofia (Ribeiro et al, 2016). A 7 de Janeiro de 2016, com imagem de Afonso Pimentel e Diogo Dias, era publicado o vídeo "Sofia Ribeiro Rapa o Cabelo - Confia”. A preto, branco e cinzento, sem som de vozes, deixando ressoar as notas de uma guitarra acústica, o vídeo conta o início de uma história de doença. Diagnosticada com um cancro da mama, Sofia juntou amigos à sua volta, num pedaço de rochedo perto do Mar, do rebentar das ondas. Uma tesoura serve de objeto de afeto entre Sofia e a sua rede de gente, cortando mechas e madeixas, numa troca de força, abraços e afetos. Não se escondem angústias nem lágrimas, elas também caem como os cabelos. São eles que escolhem deitá-los ao chão. O cabelo é rapado, o vídeo ganha cor de fogo, a música cresce, o grupo abre-se em gargalhada e Sofia olha para nós, para quem vê, para as/os outras/os que têm cancro ou que podem vir a ter.

Planeado para Outubro de 2017, com imagem e edição de Catarina Rodrigues, numa colaboração com as jornalistas Catarina Parkinson e Patrícia Domingues, é publicado o vídeo "Passar das Marcas”, saído das páginas online da "Vogue" Portugal (Rodrigues et al, 2017). O vídeo, a preto e branco, é feito como quem tira uma fotografia, apanhando mulheres quietas, de gestos suaves e breves. As imagens são acompanhadas pelas suas vozes e testemunhos, legendadas em Inglês, tentando alcançar outros olhos e públicos. Dez mulheres, despidas da cintura para cima, todas em calças de ganga, mostram mamas, cicatrizes de mastectomia e volumes de reconstruções, vestidas de igual e despindo diferenças. Um ramo de orquídea e um de estrelícia passaram-lhes pela mão, uma beleza frágil, cortada pelo pé, agarrada enquanto não murcha, enquanto não morre, tal como a vida. Num armazém vazio, as dez mulheres mostram e dizem o que é o cancro, como se reinventa um corpo, como viver e encher o tempo que resta, seja ele muito ou pouco.

No segundo dia do ultimo mês de 2017, nas páginas do "Instagram", abria-se o "Sweet December Project". Esta doce "procura de beleza no inesperado" resulta de uma experiência amarga, de um corte feito no corpo, do cancro à mastectomia, e de uma relação cortada, já feia, com um homem que não quis aceitar nem compreender a mudança. Dezassete sequências fotográficas, intervaladas por seis retratos, são exercícios de amor e afeto, da mulher que se ama a si mesma, sem precisar de outra metade para ser inteira, sem mama direita 
nem namorado torto. Já nos quarenta, celebrados no mesmo Dezembro, Ana mostra tudo, preto no branco, da cintura para cima, debaixo de água corrente e da corrente elétrica, entre lâmpadas e grinaldas de luzes. As fotografias têm som, música e palavras, escritas e ditas por ela, ouvidas por quem vê. O torso e o rosto contam a história, os gritos e choros compridos, os sorrisos e risos largos, as lágrimas que sujam, que lembram as dores e perdas, a água que lava, que põe tudo para trás. Ana Paula faz músculo, num braço de ferro contra a escuridão, a luz parece pouca, mas a força que vem de dentro faz o caminho, aqui e agora, “abraçando a incerteza, sem expectativas”, agarrando os dias e o tempo que tem pela frente. Fechando a história, Ana sabe que estamos deste lado, é o olho que nos espreita, a boca que nos diz que "nada voltará a ser igual".

Em Abril de 2018, "Chaga", de Leonel de Castro, um ensaio fotográfico sobre o cancro da mama vivido por mulheres, recebia o "Prémio Estação Imagem 2018" na categoria de retrato. Ordenando os nomes das oito mulheres retratadas, Ana Paula, Carmen, Célia, Cristina, Diana, Isadora, Patrícia e Sílvia têm nomes diferentes mas histórias parecidas, tiveram cancro da mama, viveram entre mastectomias e reconstruções, fizeram quimioterapia ou radiação, algumas em remissão, outras em processo de metastização, com a doença estendida aos ossos e ao cérebro. Seis viram as relações amorosas terminar pelo desinteresse e afastamento do par, durante ou depois do tratamento. Apenas duas permanecem com os companheiros, reforçando o casal, o amor que os junta. Usando palavras de cariz religioso, calvário e via sacra, a sinopse do projeto sublinha o corpo afligido pela doença e pela agressividade dos tratamentos, a chaga no peito, a dor que se traz. Nome próprio e apelido, idade, estádio do cancro, o número de sessões e ciclos dos tratamentos feitos, as pessoas que têm na vida, fazem os textos que acompanham as fotografias. Despidas da cintura para cima, nem todas estão sozinhas, três estão acompanhadas pelos filhos e uma pelo marido, partilhando afetos e intimidade, abraçadas, deitadas, dando o peito à amamentação. Três destas mulheres têm metástases, dando o seu rosto e testemunho em nome das muitas que morrem, aqui e no mundo. Para quem as olha, não reconhecer as histórias de doença, não participar na "luta", não dar apoio ou acompanhamento, é um segundo abandono, um desapego coletivo e público.

Enquanto escrevia estas linhas, já existiam dois projetos adicionais em andamento. O primeiro, “Eu Venci”, uma colaboração entre a fotógrafa Carla Bessa e a Liga Portuguesa Contra o Cancro (Bessa e LPCC, 2017), pretende recolher "a imagem e o testemunho" de mulheres com cancro da mama, com o objetivo de criar "esperança” para outras. O segundo, "Zumbaween”, uma parceria entre a equipa do "Mama_Move” - Serviço de Oncologia Médica do Centro Hospitalar de Gaia/Espinho, e as fotógrafas Priscila Ferreira e Carla Bessa, aproveita a "estética festiva do Halloween" e o último dia de Outubro 
para registar e divulgar o uso do "exercício físico adaptado e supervisionado" na recuperação e resistência em remissão de mulheres com cancro da mama, focando a objetiva da câmara nas participantes (Mama_Move, Ferreira e Bessa, 2018). Este crescimento mostra que estas criações visuais são uma oportunidade para a multiplicação, por inspiração ou imitação, de outras imagens, uma abertura expressiva e narrativa para outras mulheres e homens.

\section{Histórias e imagens de homens com cancro da mama e de mulheres com outras doenças malignas}

Embora os projetos artísticos portugueses sobre cancro sejam maioritariamente estruturados em torno da experiência das mulheres e do cancro da mama, a produção criativa também abarca histórias de homens e outras formas de doença oncológica. A campanha de sensibilização "Despir o Preconceito”, numa parceria entre o designer Filipe Inteiro e a Associação Cancro com Humor, não fala em tipologias de cancro, mas centra-se em mulheres jovens, da cintura para cima (Inteiro, 2013). Em finais de 2013, as fotografias de mulheres em roupas coloridas e expressões maquilhadas, são rematadas por frases de motivação, onde o riso, o sorriso e a alegria são a legenda da doença oncológica. Só as cabeças estão despidas, mostrando em público a pele careca, os cabelos curtos e os lenços que revestem o tratamento. "Despir o Preconceito" também saiu para a rua, em cartazes, nos passeios onde todas/os caminham, abrindo olhos e outras formas de ver o cancro.

Em Outubro de 2015, surgia no contexto português uma série alternativa de imagens e histórias. Com fotografias de José Ferreira e texto de Fátima Cardoso, oncologista e diretora da Unidade de Mama do Centro Clínico Champalimaud, "Men's Breast Cancer" apresenta-nos os torsos mastectomizados de dez homens, preto no branco, saídos da sombra para a luz (Ferreira, 2015). Com " $1 \%$ do total de cancros da mama diagnosticados, com trezentos e cinquenta novos casos e trinta mortes anuais”, a exposição da experiência destes homens abre uma possibilidade contra o silêncio, a invisibilidade, o preconceito, a vergonha e o desconhecimento. O projeto pretende contribuir para a compreensão destas histórias, das dificuldades, necessidades e reivindicações que se entranham nelas, ajudando a estruturar o suporte público e social essencial a qualquer resistente oncológico, da prevenção ao tratamento, deixando as imagens servir de espelho a outros homens, mamas e cicatrizes.

Saltando de 7 para 8 de Março de 2016, entrando no Dia da Mulher, com o título "IPO", curto e direto, com fotografia de Margarida Mendes Ferreira e edição de Jaromir Wimmer, uma sequência de imagens a preto e branco é apresentada como "um filme dedicado a todas as mulheres com cancro" (Ferreira e Wimmer, 2016). As mulheres são vinte e cinco e todas têm rosto, nome e apelido, dando uma data aos cancros que tiveram ou têm, enfiados nos 
aniversários das suas vidas, dos treze aos cinquenta e dois anos. Os números do cancro são escritos a giz branco sobre um quadro de ardósia, como conta de somar e subtrair, num corpo que também é escola, que também ensina. As fotos de rosto, de corpo fechado em roupa, são seguidas de fotografias de peitos e uma barriga, onde os carcinomas da mama se juntam a um cancro do colo do útero, todos desenhados nas linhas fechadas de cicatrizes, no meio da vida.

Em Novembro de 2016, desenhava-se a história de “Juju e o Zézinho", num blog e página pública da Internet (Yamagishi, 2016). Diagnosticada com um carcinoma do ovário aos trinta e quatro anos de idade, Joana Spranger Yamagishi resolveu dar forma ao seu cancro, arredondou-o, deu-lhe dentes compridos, cor azul e um nome, chamou-lhe Zézinho, pondo-lhe um acento. Semelhantes a banda desenhada, aos retângulos e sem quadradinhos, feitos a lápis e caneta, os desenhos de traços naïf estendem a história do diagnóstico às consultas e exames de rotina, já em remissão. Com imagens e palavras carregadas de humor, descritas como "rabiscos e desabafos", com alguns sustos, dores e cansaços, Joana quer dar corpo e voz ao cancro do ovário, participar na consciencialização social. Joana já tem duzentos “seguidores”, gente que aprende com desenhos simples como viver com a doença, dar-lhe um uso e um fim.

\section{Cruzando e somando as experiências de mulheres e homens entre arte(s) e cancro(s)}

A literatura apresentada pela ciência social sobre os sentidos e usos da arte na experiência da doença oncológica, manteve-se focada, quase exclusivamente, nos projetos de mulheres com cancro da mama, centrando-se noutras geografias e contextos culturais. Este texto, ao trazer projetos portugueses para o centro da análise, pretende alargar a abordagem antropológica e sociológica relativamente à pessoa doente, reunindo diversas experiências e formas de cancro vividas por mulheres e homens, recolhendo os testemunhos que carregam os seus conhecimentos. Ambicionando adicionar conhecimento inovador aos estudos sociais da arte e da doença, que outras contribuições trazem as mulheres e os homens Portugueses à forma como entendemos e agimos sobre o cancro? Que reflexões podemos retirar desta pequena lista de projetos artísticos e criativos? Estes projetos e histórias ajudam-nos a compreender algumas das dificuldades vividas por gente com cancro, mas também os recursos e resistências que são capazes de mobilizar como mulheres e homens com agência criativa, ou seja, usando a arte como uma ação para produzir mudança em si, nos outros, na comunidade. Feitos por profissionais e amadores, entre resistentes, fotógrafas/os e outras/os criadores de imagem, acumulados em pouco mais de seis anos e meio, estes projetos pouco ultrapassam a dezena e meia de criações, mas obrigam-nos a repensar a pessoa doente, o corpo, o cancro e a própria 
arte, alterando gradualmente o entendimento público e coletivo sobre estas mesmas realidades.

Relativamente ao cancro da mama, a fotografia e o vídeo permitiram despir casacos, camisolas, camisas e sutiãs, expondo cicatrizes de mastectomias, a forma exterior dos implantes e o contorno das próteses mamárias. Despidas em público, mulheres e imagens abrem a sociedade Portuguesa aos corpos e torsos que contam histórias e mostram marcas de doença, dando os seus rostos e nomes, mostrando tudo. Aquelas que expõem a nudez por inteiro, quebram o estereótipo daquilo que uma mulher pode mostrar em público, da cicatriz funda e rasgada no peito, à falta de pêlos púbicos, despegados pelo tratamento. Fotografias e vídeos mostram também a diversidade etária dos muitos corpos afetados pelo cancro da mama, dos vinte e poucos anos de uma Alexandra acabada de diagnosticar, com uma vida pela frente, às muitas décadas de Amélia, quase no fim, encostando peles jovens e lisas às envelhecidas e plissadas pelo tempo. Também mostram o lado quantitativo da doença e da sua incidência, juntando num mesmo estúdio e projeto, mulheres desconhecidas com a mesma doença, usando a cabeça e o corpo para partilhar o cancro e os efeitos do tratamento, mostrando a força conjunta e solidária de várias dezenas de vidas. Estes projetos também permitiram unir pacientes, resistentes, família e amigos, instituições oncológicas, pessoal hospitalar, equipas de maquilhagem e de consultoria de imagem, fotógrafos, jornalistas e realizadores, numa rede de interesse em torno do cancro, informando e consciencializando, fazendo e dando uso a imagens e palavras de intervenção. Fotografias e vídeos apanham lágrimas de sofrimento e sorrisos rasgados de vitória, mostrando os muitos momentos e emoções que fazem a doença. Também (re)vestem e pintam cancros e corpos com cores felizes, mostrando as "guerreiras, rainhas, princesas, deusas e amazonas" que enchem o imaginário da "luta” contra o cancro (Sontag, 2002), deixando lugar para mulheres com a roupa de todos os dias, as resistentes sem superpoderes, que caminham entre nós. Fotografias e vídeos também levaram o cancro e a cicatriz para o interior das revistas do corpo perfeito e bem vestido, em sessões fotográficas e filmadas onde mulheres sem mamas e sem roupa da cinta para cima são artigo de Vogue. O cancro também chegou às capas de revistas do jornalismo, saídas do quiosque para as mãos de quem lê, onde uma só mulher pode mudar o olhar e o entendimento de quem vê.

Quanto a outros corpos, órgãos, cancros e identidades, a fotografia permitiu juntar mulheres com cancros diferentes e atitude positiva, deixando sorrisos e frases motivacionais, ensinando como se põe o medo e a dor de lado, fora da imagem. Em campanha pelas ruas, levantados em outdoors, os corpos de cabeça careca saem de casa e do hospital, das portas para fora, puxando pelo olhar de quem passa. Juntando raparigas adolescentes e mulheres de todas as idades, carregando cancros e cicatrizes em órgãos diferentes, estes projetos também apontam para a fragilidade e força de todos os corpos e partes, 
alertando para a necessidade de vigilância e prevenção em todas as idades. A fotografia também trouxe para debaixo da luz e da câmara as experiências de homens com cancro da mama, as suas queixas, perdas e forças, as histórias raras e intrincadas que desfazem mistificações relativas ao género da doença. O cancro do ovário foi o primeiro a passar para o papel do desenho, numa história comprida que conta todos os detalhes, feita a caneta e lápis de cor. Do diagnóstico às consultas de rotina, expõem-se os medos e esperanças, as particularidades de outra(s) doença(s) oncológica(s), mostrando que o cancro é feito de gente, espaços, objetos e substâncias, daquilo que se sente, faz e pensa, desejando a saúde e a remissão. Feitos em estúdio, na rua ou em paisagens criteriosamente escolhidas, fotografias, vídeos e desenhos são carregados para a Internet, onde os tempos e espaços se juntam, onde as histórias e imagens de cancro estão sempre disponíveis para os outros, em digressão permanente, atravessando as fronteiras de países e corpos.

Das histórias compridas contadas em desenho e fotografia, aos projetos feitos num dia ou em poucas horas, as imagens de cancro feitas por e com mulheres e homens Portugueses já têm efeito no Mundo. Misturando corpos, cancros e artes, mobilizam e mudam quem vê, refazendo e alargando a imagética coletiva e o conhecimento público da doença oncológica. Nem todas as imagens comentadas neste texto são bonitas de ver, o cancro não tem forma de laço nem cor de flor. A doença oncológica é feita de muitas violências, dores e perdas, as suas verdades são cruas e duras, vincadas no corpo e na vida. Ainda existe quem feche os olhos, vire a cara ou denuncie estas imagens de cancro, embora os efeitos positivos destes projetos e campanhas de sensibilização e ativismo anulem os defeitos de qualquer forma de censura.

\section{Conclusão}

Nestes projetos, o corpo e a pessoa doente não se apresentam como realidades enfraquecidas, frágeis ou incapacitadas, apontando para a agência reforçada de gente que resiste à doença, ao tratamento e aos impactos subtrativos dos dois, diminuindo o cancro pela resistência. O cancro não é apenas uma experiência destrutiva, mas também um processo que implica a aquisição de capacidades e conhecimentos que podem ser postos em prática. O cancro estende-se na arte e nas suas imagens, ganhando um outro formato visual e material, tornando-se experiência adicional, capaz de alcançar outros corpos e vidas. A arte puxa o cancro para fora dos limites da pele, permitindo que o mesmo seja partilhado, visto, sentido e pensado por outras pessoas. Ao colocar o cancro em imagem, a arte torna-se uma extensão ontológica da doença, uma forma de conhecimento e ação transformativa, ajudando a compreender e refazer experiências individuais, estendida, depois, à comunidade. A disponibilização pública destes projetos e imagens carrega a intenção de iniciar no contexto local um processo de 
ramificação positiva do cancro, retirando-o do seu lugar primário, estendendo-o a outros corpos, lugares e entendimentos. Todas estas imagens pretendem ter impacto na realidade social e coletiva, procuram mudar e acrescentar novos gestos às nossas ações sobre a doença oncológica. Nestes projetos, impregnados das particularidades e reivindicações de mulheres e homens Portugueses com cancro, a arte sai à rua e entra nas páginas da Internet, feita ferramenta de intervenção e ativismo em saúde e oncologia. Tal como as palavras (Austin, 1962), a arte "faz coisas" (Gell, 1998; Knappett, 2006), dá conhecimento. Imbuída de intencionalidade e agência, é ação com efeito, provocando sensações, emoções e pensamentos, procurando mudar gente, coisas e mundo.

A ciência também é feita deste desejo de mudar a realidade, os nossos textos e investigações também procuram ser consequentes. Atravessando as estatísticas referentes a Portugal (Miranda et al, 2016), repetindo o padrão também esperado para o resto do mundo (WHO, 2017), a incidência do cancro aumentará nas próximas duas décadas. A cada ano, Portugal tem quarenta e cinco mil novos casos de cancro e mais de vinte e cinco mil mortes por ano, uma média de setenta mortes por dia, um quarto da soma de todos os óbitos. Descurando estes números, não existe suficiente investigação em ciência social sobre as várias formas e estádios de cancro que temos e vivemos, uma lacuna agravada pela desatenção das nossas disciplinas ao conhecimento de quem vive a doença. Em Portugal, os estudos antropológicos ou sociológicos sobre gente com cancro são diminutos, impedindo o resto da sociedade de reconhecer ou aceder de forma informada às suas experiências. Compreender uma fracção destas histórias de cancro, procurando as suas diferenças e semelhanças, poderá providenciar a informação e o conhecimento necessário para um alargamento da forma como o vivemos, sentimos e pensamos, não só como indivíduos mas enquanto comunidade. Ao informar e afetar outros, unidos no risco, convocados para uma agência partilhada, podemos estruturar um contexto relacional e comunitário solidário no qual a resistência de pacientes e famílias se possa alicerçar.

Num momento em que a incidência de cancro dobra números e vidas, precisamos de uma ciência inclusiva e de uma sociedade reflexiva, ou seja, uma coprodução de conhecimento que envolva os cidadãos na investigação e produção científica, reunindo a riqueza de saberes que recheiam os seus corpos. De acordo com este objetivo, é necessário alargar o entendimento da comunidade Portuguesa sobre a diversidade de experiências que dão forma ao cancro, desmistificando e informando, trazendo os saberes de quem vive a doença oncológica para o centro do debate público e científico. Os projetos visuais e criativos de gente doente e resistente são os primeiros a estimular esta estratégia, possibilitando a produção de um conhecimento sobre a doença que pode ser visto e lido nos textos que os acompanham, explicando o cancro. O cancro não é apenas crescimento celular anormal ou massa tumoral, é história com rosto e 
nome de mulheres e homens. O cancro é fotografia, vídeo e desenho criativo, entrando nos olhos e corpos dos/as outros/as, mudando de forma e de sítio. O cancro faz-se arte, entre imaginação, conhecimento e ação, feito de muitas partes. Quem o fotografa, filma e desenha e quem se deixa fotografar e filmar, quer e pede que a doença oncológica seja vista, sentida e desfeita por todas/os, unindo doentes, resistentes, famílias e comunidade, no hospital, em casa e na rua, usando as redes e espaços da Internet para chegar mais longe.

\section{Referências bibliográficas}

AUSTIN, John L. (1962), How To Do Things With Words, Cambridge, Harvard University Press.

BANKS, Marcus; Zeitlyn, David (2015), Visual Methods in Social Research, Thousand Oaks, Sage Publications.

BELL, Susan E. (2002), "Photo images: Jo Spence's narratives of living with illness", Health 6:1, pp. 5-30.

BELL, Susan E. (2006), "Living with breast cancer in text and image: making art to make sense", Qualitative Research in Psychology, special issue on "embodiment" 3:1, pp.31-44.

BOLAKI, Stella (2017), Illness as Many Narratives: Arts, Medicine and Culture, Edinburgh, Edinburgh University Press.

BUTLER-KISBER, Lynn (2010), Qualitative Inquiry: Thematic, Narrative and Arts-Informed Perspectives, Thousand Oaks, Sage Publications.

DENZIN, Norman K.; Lincoln Yvonna S. (eds) (2017), The Sage Handbook of Qualitative Research, Thousand Oaks, Sage Publications.

DeSHAZER, Mary K. (2015), Mammographies: The Cultural Discourses of Breast Cancer Narratives, Ann Arbor, University of Michigan Press.

GELL, Alfred (1998), Art and Agency: An Anthropological Theory, Oxford, Clarendon Press.

GRAY, Ross; Sinding, Christina (2002), Standing Ovation: Performing Social Science Research About Cancer, Walnut Creek CA, AltaMira Press.

HARAWAY, Donna (2004), "Situated Knowledges: The Science Question in Feminism and the Privilege of Partial Perspective", in Sandra Harding, (ed.), The Feminist Standpoint Theory Reader: Intellectual and Political Controversies, New York, Routledge, pp. 81-102.

HARDING, Sandra (1991), Whose Science? Whose Knowledge? Thinking from Women's Lives, Buckingham, Open University Press.

HARDING, Sandra (2004), "Introduction: Standpoint Theory as a Site of Political, Philosophic and Scientific Debate" in Sandra Harding, (ed.), The Feminist Standpoint Theory Reader: Intellectual and Political Controversies, New York, Routledge, pp. 1-16.

KNAPPETT, Carl (2005), Thinking Through Material Culture: An Interdisciplinary Perspective, Philadelphia PA, University of Pennsylvania Press.

MASON, Jennifer (2002), Qualitative Researching, Thousand Oaks, Sage Publications.

McMULLIN, Juliet (2016), "Cancer and the Comics: Graphic Narratives and Biolegitimate Lives”, Medical Anthropology Quarterly 30(2):149-167.

MIRANDA, Nuno et al, (2016), Portugal Doenças Oncológicas em números - 2015 (Programa Nacional Para as Doenças Oncológicas), Lisboa, Direção-Geral da Saúde.

NORONHA, Susana de (2009), A Tinta, a Mariposa e a Metástase: A Arte como Experiência, Conhecimento e Acção sobre o Cancro de Mama, Porto, Afrontamento. 
NORONHA, Susana de (2015), Objetos Feitos de Cancro: Mulheres, Cultura Material e Doença nas Estórias da Arte, Coimbra, Almedina.

NORONHA, Susana de (2018), "Fotografías hechas de cáncer: el arte como pieza de la enfermedad en las historias contadas por mujeres”, in Rebeca Pardo e Montse Morcate (eds.), Representar el dolor: muerte, enfermedad y duelo, Barcelona, Sans Soleil Ediciones.

O BRIEN, Sharon (2013), "Showing the Voice of the Body: Brian Fies s Mom s Cancer, the Graphic Illness Memoir, and the Narrative of Hope", in Jane Tolmie, (ed), Drawing from Life: Memory and Subjectivity in Comic Art, Ridgewood, University Press of Mississippi.

PINK, Sarah (2005), The Future of Visual Anthropology: Engaging the Senses, London, Routledge.

RADLEY, Alan (2002), "Portrayals of Suffering: on Looking away, Looking at, and the Comprehension of Illness Experience”, Body \& Society, 8:3, pp. 1-23.

RADLEY, Alan; e Susan E. Bell (2007), "Artworks, Collective Experience and Claims for Social Justice: The Case of Women Living With Breast Cancer”, Sociology of Health \& Illness, 29, pp. 366-390.

RADLEY, A. (2009), Works of Illness: Narrative, Picturing and the Social Response to Serious Disease, Leicestershire, InkerMen Press.

SANTOS, Boaventura de Sousa (org.), (2004), Semear Outras Soluções: Os Caminhos da Biodiversidade e dos Conhecimentos Rivais, Porto, Afrontamento.

SANTOS, Boaventura de Sousa (2007), "Beyond Abyssal Thinking: from Global Lines to Ecologies of Knowledges”, Review, XXX-1, pp. 45-89.

SCHNEIDER, Arnd; Wright, Christopher (eds.), (2005), Contemporary Art and Anthropology, Oxford, Berg Publishers.

SONTAGE, Susan (2002), Illness as Metaphor and AIDS and Its Metaphors, London, Penguin.

SPENCE, Jo (1986), Putting Myself in the Picture: A Political, Personal and Photographic Autobiography, London, Camden Press.

SPENCE, Jo (1995), Cultural Sniping: The Art of Transgression, London, Routledge.

WILKE, Hannah (1995), Intra Venus, New York, Ronald Feldman Fine Arts.

WHO, World Health Organization (2017) Cancer: Fact Sheet, Disponível em http://www.who. int/mediacentre/factsheets/fs297/en/ [consultado em: 02/02/2018].

WOODWARD, Ian (2007), "Material Culture, Narratives and Social Performance" in Understanding Material Culture, Thousand Oaks, Sage Publications.

\section{URL's consultadas}

AMARAL, Bruna; Conde, Amélia (2012) Nu Enfermo [Fotografia], disponível em http://cargocollective.com/brunaamaral/Nu-Enfermo [consultado em: 02/02/2018].

BAIÃO, Ana; Medeiros, Fátima; Martins, Ana (2013) Cicatrizes para a Vida [Fotografia], disponível em http://expresso.sapo.pt/podcasts/2017-03-08-Como-esta-fotografia-mudou-a-vidadesta-mulher [consultado em: 02/02/2018].

BESSA, Carla; LPCC (2017-2018) Eu Venci [Fotografia], disponível em https://www.ligacontracancro.pt/www/uploads/nr-norte/mkt/pub-sessao-fotografica-eu-venci-2017-79.jpg [consultado em: 02/02/2018].

BRAGA, Tiago (2016) Na Minha Pele [Fotografia; Vídeo], disponível em https://www.facebook. $\mathrm{com} / \mathrm{pg} /$ naminhapeleproject/photos/?tab=album\&album_id=1733367140262238 [consultado em: 02/02/2018].

CASTRO, Leonel de (2018) Chaga [Fotografia], disponível em

http://www.estacao-imagem.com/pt/premio/2018/vencedores [consultado em: 20/07/2018]. 
CUNHA DE SÁ, Gonçalo (2011) Breast Cancer, Live to Tell ou 100 Mulheres 100 Cancro [Fotografia], disponível em https:/cunhadesa.wordpress.com/2016/09/28/breast-cancer-live-to-tell/ [consultado em: 02/02/2018].

FERREIRA, José (2015) Men's Breast Cancer [Fotografia], disponível em http://www.joseferreira-photographer.com/7445784/men39s-breast-cancer [consultado em: 02/02/2018].

FERREIRA, Margarida M.; Wimmer, Jaromir (2016) IPO [Fotografia], disponível em https:// www.youtube.com/watch?v=jPQ7R2xPk_U [consultado em: 02/02/2018].

INTEIRO, Filipe (2013) Campanha Despir o Preconceito [Fotografia], disponível em https:// www.facebook.com/media/set/?set=a.583955538306492.1073741847.467589476609766\&t ype $=3$ [consultado em: 02/02/2018].

LOPES, Ana Paula [Ana Bee] (2017) Sweet December Project [Fotografia], disponível em https:// www.instagram.com/sweetdecemberproject/ [consultado em: 20/07/2018].

MAMA_MOVE; Ferreira, Priscila; Bessa, Carla (2018) “Zumbaween” [Fotografia], disponível em https://www.facebook.com/events/254288825429987/ [consultado em: 30/10/2018].

MEF; APAMCM (2011) Retrato de Mim [Fotografia], disponível em https://www.facebook.com/ $\mathrm{media} / \mathrm{set} /$ ?set=a.10151408088361126.1073741829.134313181125\&type=3 [consultado em: 02/02/2018].

MORADO, Nádia; Braga, Tiago (2014) Calendário AOA 2014, Um Projecto de Luta Contra o Cancro [Fotografia], disponível em https://www.facebook.com/pg/FotografiaSolidária-523996474306002/photos/?tab=album\&album_id=592920130746969 [consultado em: 02/02/2018].

MORADO, Nádia; Braga, Tiago (2015) Once Upon a Dream [Fotografia], disponível em https://www.facebook.com/pg/Once-Upon-a-Dream-308246952655738/ photos/?tab=album\&album_id=399302710216828 [consultado em: 02/02/2018].

RIBEIRO, Sofia; Pimentel, Afonso; Dias, Diogo (2016) Sofia Ribeiro Rapa o Cabelo - Confia [Vídeo], disponível em https://www.youtube.com/watch?v=8IuzTeCRye8 [consultado em: 02/02/2018].

RODRIGUES, Ana C.; Parkinson, Catarina; Domingues, Patrícia (2017) Passar das Marcas [Vídeo; Fotografia], disponível em https://vimeo.com/235936377[consultado em: 02/02/2018].

SILVA, Alexandra; Basto, Eduardo (2011) My Body is a Cage [Fotografia], disponível em http:// my-body-is-a-cage-blog.tumblr.com/ [consultado em: 02/02/2018].

YAMAGISHI, Joana S. (2016) Juju e o Zézinho [Desenho], disponível em https://www.facebook. com/pg/Jujueozezinho/photos/?ref=page_internal [consultado em: 02/02/2018]. 